\title{
The Behaviour of Meiotic Chromosomes as Revealed through the Use of Bavistin on Pea
}

\author{
S. S. Choudhary and S. M. Sajid \\ Bioscience Research Centre, Department of Botany, \\ T. N. B. College, Bhagalpur-812007, India
}

Accepted November 8, 1984

Besides agricultural crop, all the living organisms, including human beings are exposed to a variety of pesticides, insecticides, fungicides and other such agrochemicals used by the farmers. It is well known that majority of these agrochemicals cause cytogenetic hazards in plants as well as animals (D'Amato 1950, Sharma and Talukdar 1965, Wuu and Grant 1967, Epstein and Legator 1971, Amer and Farah 1976, Nasar and Singh 1980, Choudhary and Sajid 1981). Certain agrochemicals are believed to be mutagenic, teratogenic and even carcinogenic. Therefore, it is desirable that all such groups of agrochemicals must be studied for their cytogenetic and mutagenic action as has been suggested by Lederberg (1971). Studies on meiotic behaviour of chromosomes are meagre. Most of the work have been done on Allium, Vicia, Barley, Gossypium, Drosophila, etc. Pulse crop has largely been neglected. Sybenga (1975) has mentioned that counting of chismata is equivalent to measuring the crossing over rate and it is one of the several ways to assess the recombination rate of genetic material. Therefore, in the present work an attempt has been made to study the meiotic effect of Bavistin before and after spraying the fungiside (Bavistin) on pea in $M_{1}$ and $M_{2}$ generations.

\section{Materials and methods}

For the present study two varieties of pea i.e. Pisum sativum L. cv. BR/12 and $P$. sativum L. cv. T/169 were selected. Marketed sample of "Bavistin"- -a broad spectrum systemic fungicide-was taken for the investigation. It has $50 \% \mathrm{w} / \mathrm{w}$ wettable powder containing $500 \mathrm{gm} / \mathrm{kg}$ of carbendazim (2-methoxy-carbamoyl benzimidazole) and $50 \%$ adjuvants (B.A.S.F., India Ltd., Bombay). The recommended dose for spraying Bavistin is $0.2 \%$ aqueous solutions. Both the varieties of pea were grown separately in different plots. Two concentrations i.e. $0.2 \%$ and $0.4 \%$ aqueous solutions of the fungicide were sprayed for three times. The controls were sprayed with distilled water. The first time spraying was done when the plants were of 20 days old. Then again after twenty days second time spraying was done. The third and last time spraying was done when the plants started developing flower buds.

For meiotic studies young flower buds were fixed in Carnoy's fluid (Darlington and $\mathrm{La}$ Cour 1962) in between $9.00 \mathrm{a}$.m. and $10.00 \mathrm{a} . \mathrm{m}$. The crops were harvested and seeds were collected from each of the plots separately, The $M_{1}$ seeds, thus obtained, were sown in the plots during the next growing season. No spraying 
was done on the plants. Meiotic studies were made in pollen mother cells (PMCs) of the $M_{1}$ generations. Seeds were collected and sown in the plots of $M_{2}$ generations. The plants of $\mathrm{M}_{2}$ generations were not sprayed. Chromosomal behaviours were studied in the PMCs of $\mathrm{M}_{2}$ generations. For this, anthers were squashed in $1.5 \%$ acetic carmine, dehydrated in butanol series and mounted in euparal. Diakinesis and metaphase-I configurations were drawn and chiasma frequencies were recorded in tabular form from permanent/temporary slides. Photomicrographs were taken from permanent slides.

\section{Observations}

Bavistin sprayed plants of $M_{1}$ and $M_{2}$ generations showed varied kinds of aberrations during microsporogenesis. Unequal distribution of chromosomes at two poles, multipolar anaphase $\mathrm{I} /$ secondary associations and stickiness were observed (Figs. 1-3).

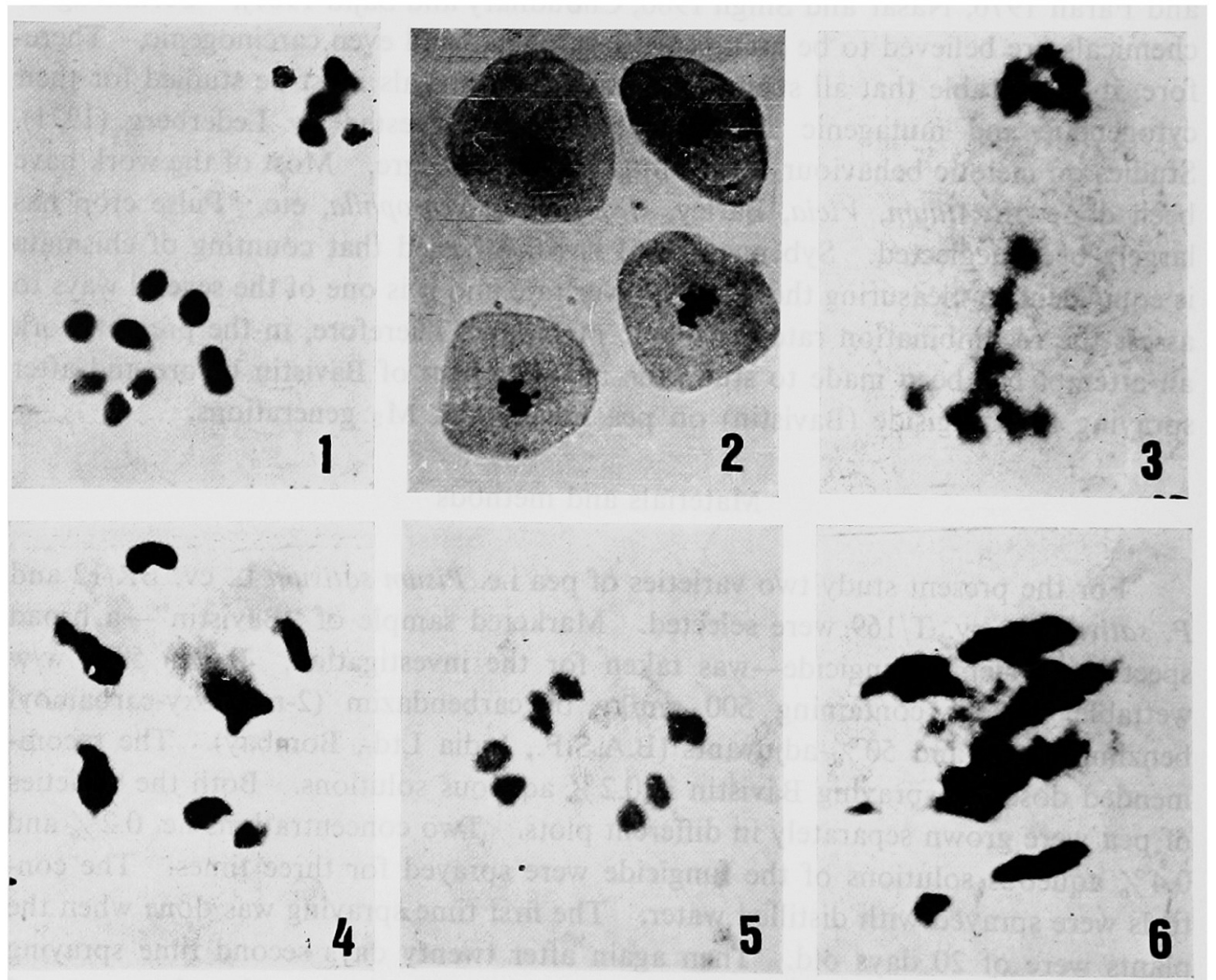

Figs. 1-6. 1, PMC showing unequal distribution of chromosomes at two poles in anaphase I after $0.4 \%$ Bavistin spray on $P$. sativum L. cv. T/169. $\times 3000$. 2, PMCs showing stickiness in metaphase I after $0.2 \%$ Bavistin spray on $P$. sativum $\mathrm{L}$. cv BR/12. $\times 1125$. 3, PMC showing laggards in metaphase I after $0.4 \%$ Bavistin spray on $P$. sativum L. cv BR/12. $\times 3000$. 4, PMC with seven bivalents in diakinesis after $0.2 \%$ Basistin spray on $P$. sativum $\mathrm{L}$. cv T/169. $\times 3500$. 5, PMC showing seven bivalents after distilled water spray (control) on $P$. sativum L. cv T/169. $\times 2525$. 6, PMC showing seven bivalents after distilled water spray on $P$. sativum $\mathrm{L}$. cv BR/12. $\times 3770$. 


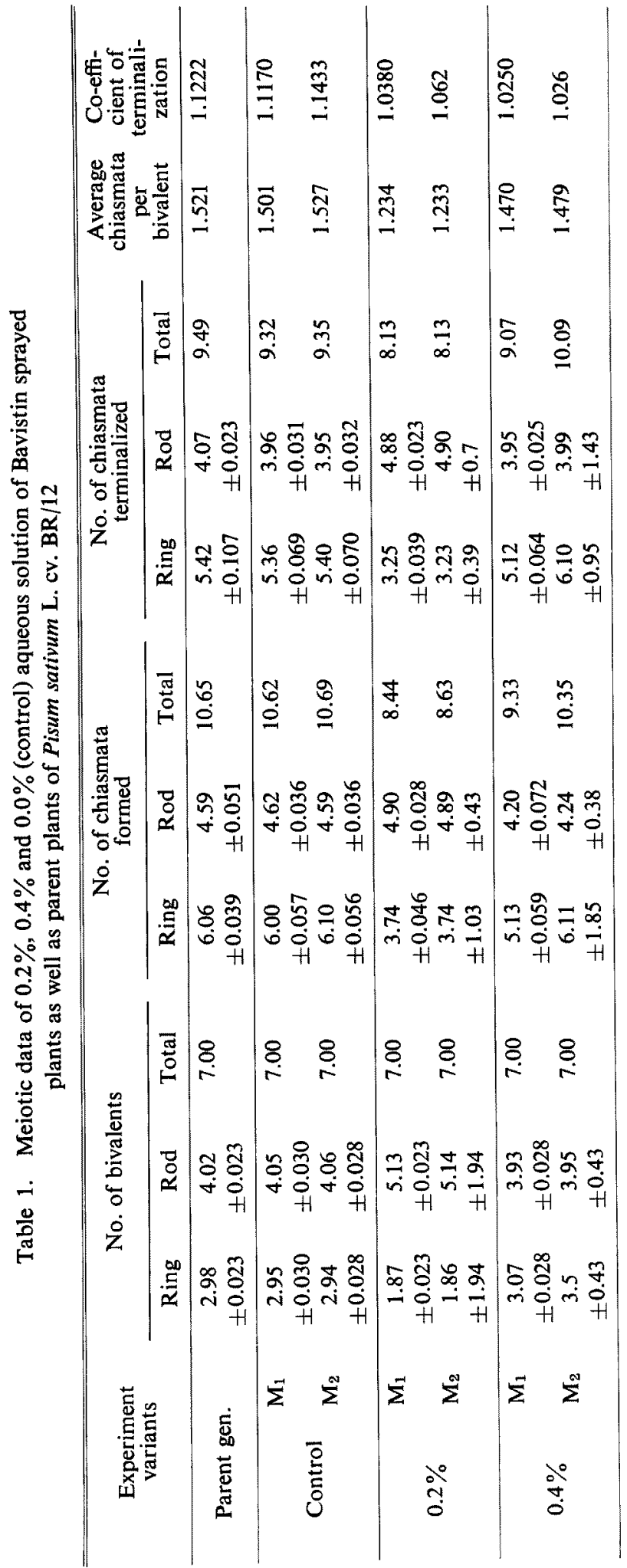




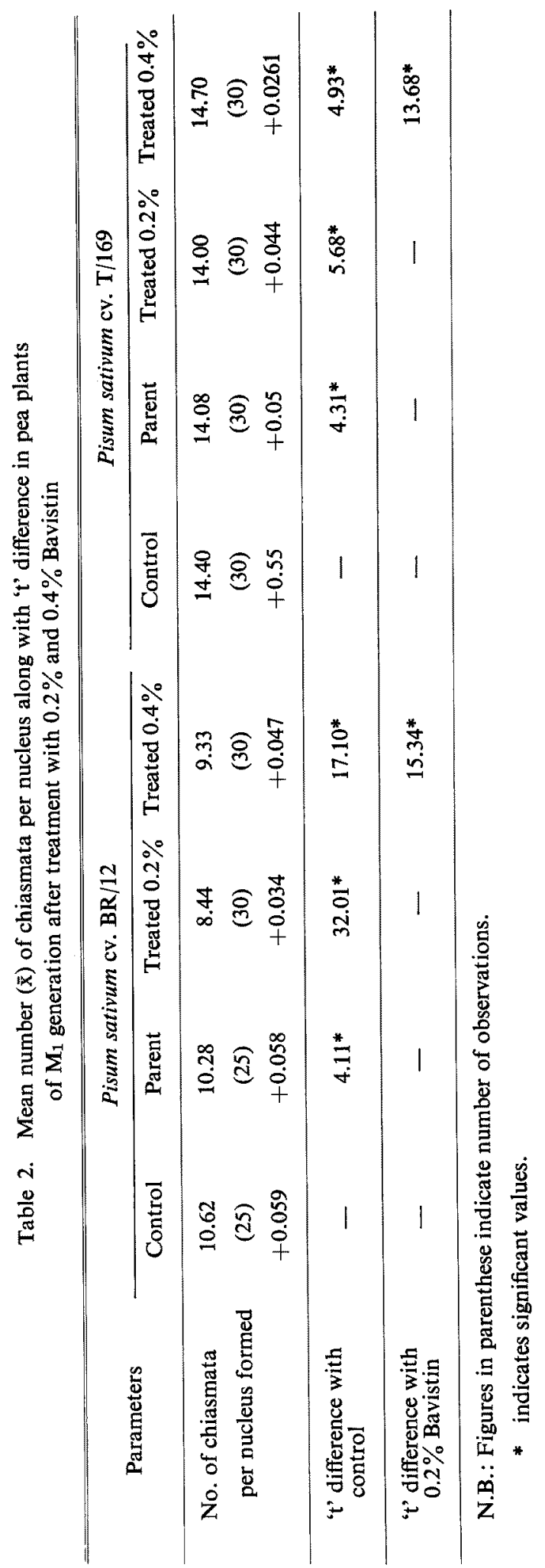




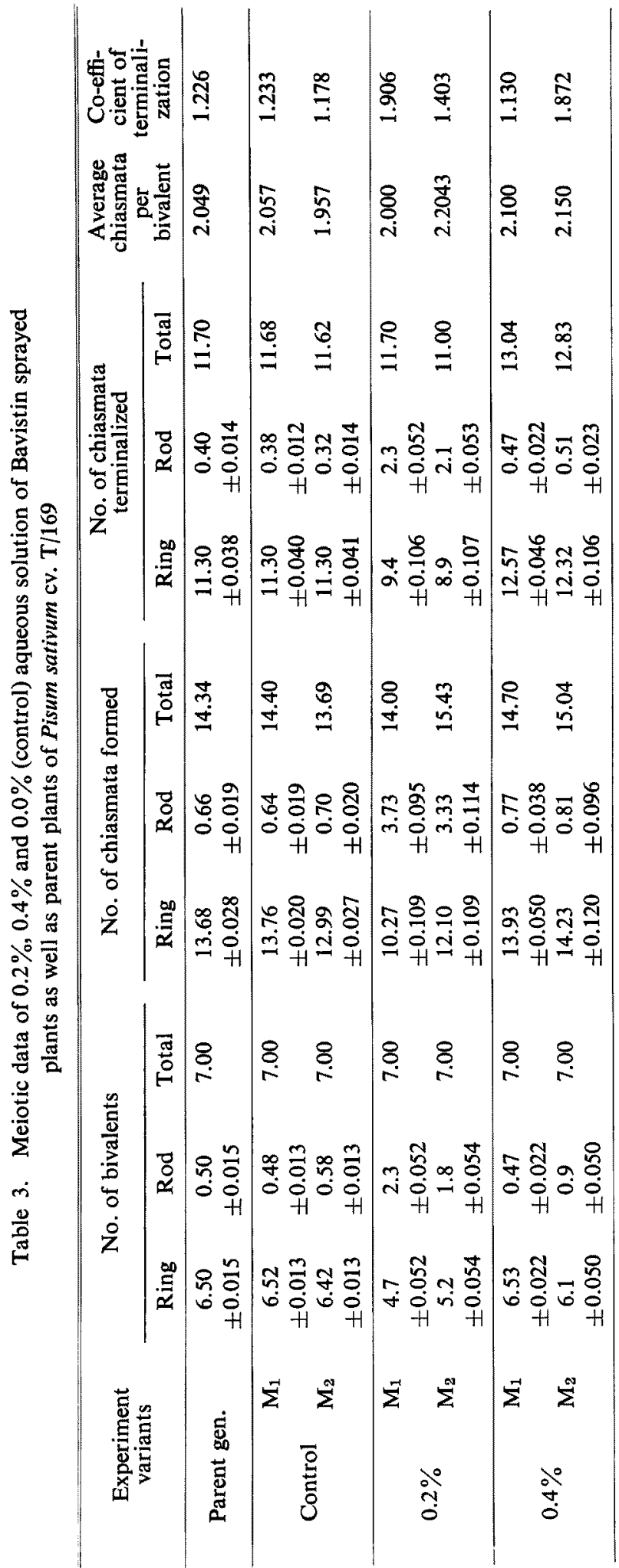


Both the varieties of pea showed seven bivalents (Figs. 4-6). The $\mathbf{M}_{1}$ progenies of $0.2 \%$ Bavistin sprayed plants of $P$. sativum cv. BR/12 indicated a decrease in the formation of ring bivalents and corresponding increase in that of rod bivalents per nucleus in comparison to control Total number of chiasmata formed were 8.44 and 9.33 in $M_{1}$ generation treated with $0.2 \%$ and $0.4 \%$ Bavistin respectively. While, it was 10.62 in the control progenies. Average chiasmata per bivalent were also lower than that of the parent (Table 1).

The progenies of $\mathrm{M}_{2}$ generations were meiotically analysed and it was observed that the number of ring and rod bivalents, total number of chiasmata formed and terminalised were maintained. Average chiasma per bivalent was less i.e. 1.233 and 1.479 in PMCs of $0.2 \%$ and $0.4 \%$ Bavistin treated plants against 1.527 in control.

The progenies in $\mathrm{M}_{1}$ generation of $P$. sativum $\mathrm{cv}$. $\mathrm{T} / 169$ sprayed with $0.2 \%$ Bavistin showed marked decrease in the number of ring bivalents formation in comparison to that of control plants. Treatment with $0.4 \%$ Bavistin did not affect the formation of ring bivalent in $\mathbf{M}_{1}$ generation. However, an increase in ring bivalent formation was recorded in $\mathrm{M}_{2}$ generation. Other meiotic characters like total number of chiasmata formed and terminalised remained almost unaffected. However, average chiasma per bivalent was 2.2 and 2.15 in $\mathrm{M}_{2}$ progenies treated with $0.2 \%$ and $0.4 \%$ Bavistin respectively against 2.0 and 1.9 in control (Table 3 ). Lower number of chiasmata per nucleus observed in $\mathbf{M}_{2}$ progenies of $P$. sativum cv. $B R / 12$ in comparison to that of control has been shown to be significant on ' $t$ ' test value (Table 2). Significant values for variation in the total number of chiasma per nucleus formed in the $\mathrm{M}_{1}$ progenies of $P$. sativum $\mathrm{cv} . \mathrm{T} / 169$ were observed (Table 4). The higher chiasma per nucleus formed in PMCs of $\mathrm{M}_{2}$ generation of both the cultivars of pea has been shown to be highly significant by ' $t$ ' test system (Tables 2, 4).

\section{Discussion}

observations made in PMCs of different generations of $0.2 \%$ and $0.4 \%$ Bavistin sprayed cultivars of pea have indicated the differences in chiasma formation and terminalisation as have been shown in Table 1, 4. Occurrence of ring bivalents indicates greater homology in between the arms of paired chromosomes and hence tendency towards autogamy i.e. self pollination (Choudhary and Roy 1982).

Physical and chemical agents causing mutations all have effects on crossing over and chiasma formation, resulting in recombination of genetic materials which is of great evolutionary significance. The presence of chiasma indicates the events of genetic crossing over and counting of chiasma is equivalent to measuring the crossing over rate. In a particular species the mean number of chiasma per nucleus has been found to be constant (Patil and Deodikar 1972, Nayer 1973). This constancy depends on various internal and external factors (Hewitt and John 1965, Kumar et al. 1978). The crossing over and chiasma frequency rate are controlled by genotype of the organism as has been suggested by Lawrence (1961) and Sinha (1964). The external factors controlling chiasma frequencies are heat shock (Plough 1967), radiation (Muller 1954), alkylating, chelating agents and metallic ions (Levine 


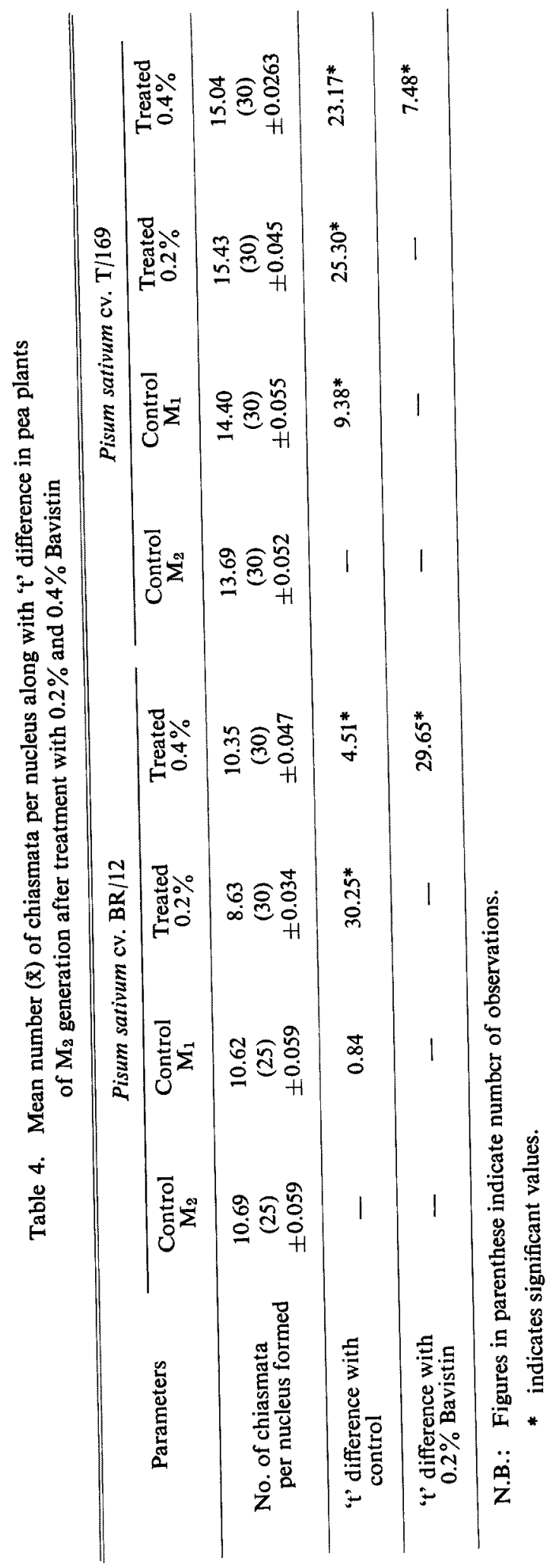


1955, Sinha and Bhagat 1975), relative amount of nitrogen and oxygen, dehydration and starvation (Ives et al. 1953, Herskowitz 1959). The exact mechanism of action of these physical and chemical agents are not well defined. However, Muller (1954) has suggested that induced crossing over is due to reciprocal chromatidal translocation. Muller (1954) has mentioned that decrease in crossing over is due to disturbances in chromosome movement during meiosis or due to interference. The other possibility for the origin of induced crossing over may be increase in cytological distance i.e. increase in chromosomal length between the genes as were observed by Yost and Benneyan (1957), Zakharov and Inge-vechtomov (1963), Sinha (1969).

As the chiasma formed in between any two loci is a function of cytological distance between them, it may be said that Bavistin, which has affected the chiasma formation, might be due to change in the degree of spiralisation of chromatin fibre. Fungicide causing despiralisation would increase the total number of chiasma formed per nucleus and that inducing spiralisation would decrease chiasma formation. Thus, it can be hypothesize that any agrochemical causing chromosome spiralisation/despiralisation/chromatidal trans-locations is capable of affecting chiasma formations. Spiralisation of chromosome is induced by radiation (Whitefield $e$ t al. 1964). Manna and Majumdar (1964) have shown despiralisation of chromosome by ethyl alcohol.

In the present investigation Bavistin has significantly decreased the chiasma formation in $\mathrm{M}_{1}$ generation of $P$. sativum $\mathrm{cv}$. $\mathrm{BR} / 12$ which was maintained in $\mathrm{M}_{2}$ generation. This decrease in chiasma formation may be due to i) change in general metabolism of cellular system (Singh and Gupta 1981) or ii) failure of parts of chromosome pairing (Elliott 1955) or iii) change in chromatidal length due to spiralisation. Slight increase in the number of chiasma formation in $\mathbf{M}_{1}$ and $\mathbf{M}_{2}$ generations of $P$. sativum $\mathrm{cv}$. T/169 has been observed which may be due to despiralisation of chromatin fibre. Therefore Bavistin may be called as recombinogenic and the effect of Bavistin is specific showing decrease in number of chiasma in one cultivar and increase in number of chiasma in other cultivar of pea.

\section{Summary}

Meiotic studies in Bavistin (a systemic fungicide) sprayed plants of Pisum sativum $\mathrm{L}$. cv. BR/12 and $P$. sativum $\mathrm{L}$. cv T/169 were made with a view to assess the effects of fungicide on chiasma frequencies upto $\mathrm{M}_{2}$ generations. The recommended dose i.e. $0.2 \%$ aqueous solution of Bavistin and higher dose i.e. $0.4 \%$ aqueous solution were sprayed on two cultivars of pea. $0.2 \%$ aqueous solution of Bavistin has caused a decrease in number of ring bivalents as well as number of chiasmata per nucleus formed in $P$. sativum cv. BR/12. Average chiasmata per bivalent were also lower in comparison to control.

An increase in number of ring bivalent formation in $M_{2}$ generation of $0.4 \%$ Bavistin treated $P$. sativum $\mathrm{cv}$. T/169 was recorded. Average chiasmata per bivalent and total number of chiasmata per nucleus formed were also higher. Lower/ higher number of ring bivalent/chiasmata formed have been shown to be significant 
by ' $t$ ' test value. The increase/decrease in the total number of chiasmata per nucleus formed may be due to i) change in general metabolism of cellular system or ii) failure of parts of chromosome pairing or iii) change in chromatin length due to spiralisation induced by Bavistin. Thus, Bavistin may be termed as recombinogenic and its meiotic effects are specific as have been recorded in two cultivars of pea in the present investigation.

\section{Acknowledgement}

The authors are grateful to Dr. A.N. Prasad, Head of the Department of Botany and Professor G.D. Jha, Principal, T.N.B. College, Bhagalpur for providing necessary facilities and encouragements.

\section{References}

Amer, S. M. and Farah, O. R. 1976. Cytological effect of pesticide VIII. Effect of carbamate pesticide IPC- "Rogor" and "Duphar" on Vicia faba. Cytologia 41: 597-606.

Choudhary, S. S. and Sajid, S. M. 1981. Effect of Bavistin on root meristem of pea. Proc. 4th All Ind. Cong. Cyt. Gen. Oct., Bhagalpur University 17-21.: 58 (Abst.).

- and Roy, R. P. 1982. Meiotic studies and taxonomic considerations in some taxa of Verbenaceae. Cytologia 47 (2): 771-777.

D'Amato, R. 1950. Notes on the chromosome breaks induced by pure gammaxene. Cytologia 2: $361-364$.

Darlington, C. D. and La Cour, C. F. 1962. The Handling of Chromosomes. 4th ed. George Allen and Unwin Ltd., London.

Elliott, C. G. 1955 . The effect of temperature on chiasma frequency. Heredity 9: 385-398.

Epstein, S.S. and Legator, M.S. 1971. The Mutagenecity of Pesticides. M. I. T. Press, Cambridge, Massachusettes: 19-27.

Herskowitz, I. H. 1959. Induced changes in female germ cells of Drosophila VI. The effect of dehydration upon the X-ray induced frequencies of crossing over like exchange and of gross chromosomal rearrangements. Genetics 44: 328-339.

Hewitt, G. M. and John, B. 1965 . The influence of numerical and structural mutations on chiasma frequency. Heredity 20(1): 123-135.

Ives, P. T., Fantom, B. J., Yost, H. T. and Levine, R. P. 1953. The effects of infrared radiations and descication on crossing over in Drosophila melanogaster. Proc. Nat. Acad. Sci. USA. 39: 1134-1141.

Kumar, H., Jha, S. K. and Singh, R. B. 1978. Effects of chromosome interchanges on chiasma frequency in Pisum sativum L. Proc. 3rd All Ind. Cong. Cyt. Gen. Haryana Agri. Univ., Hissar, Oct. 23-27: 162 (Abst.).

Lawrence, C. W. 1961. The effects of radiation on chiasma formation in Tradescantia. Radiation Botany: 92-96.

Lederberg, J. 1971. Forwords in "The Mutagenecity of Pesticides". Eds. Epstein, S. S. and Legater, H. S. M. I. T. Press, Cambridge.

Levine, R. P. 1955. Chromosome structure and the mechanism of crossing over. Proc. Nat. Acad. Sci USA. 41: 727-730.

Manna, G. K. and Majumdar, S. C. 1964. Ethyl alcohol induced sex chromosome breakage in the grasshopper, Phioeba antennata. Naturwissenschaften 24: 646.

Muller, H. J. 1954. The nature of genetic effects produced by radiation. In "Radiation Biology." Ed. A. Hollander. Mc Graw Hill, New York, Vol. I, Chap. VII,

Nasar, S. K. T. and Singh, S. 1980. Arrest of somatic cells at $\mathrm{G}_{2}$ by Sevin (pesticide). Experientia 36: 948-949. 
Nayar, N. M. 1973. Origin and Cytogenetics of Rice. In Advances in Genetics. 17: 153-264. Academic Press, London.

Patil, V. P. and Deodikar, G. B. 1972. Interspecific variations in chiasma frequency and terminalisation in Emmer wheat. Cytologia 37: 225-234.

Plough, H. H. 1967. The effects of temperature on crossing over in Drosophila. J. Exp. Zool. 24: 147-209.

Sharma, A. K. and Talukdar, S. 1965. Effects of gammaxene on pollen mother cells of Allium cepa. Biologia Bratislava 20: 105-108.

Sinha, S. P. 1964. Genetic control of spontaneous crossing over. Vestinik Leningrad Univ. Ser. Biologia 15: 130-135.

- 1969. On the after effect of irradiations. In Radiation and Radiamimetic Substances in Mutation Breeding. Dept. of Atomic Energy, Govt. of India: 26-29.

- and Bhagat, B. P. 1975. On the induction of crossing over by ethylaneamine. J. Cyt. Gen. Suppl: $187-190$.

Sinha, S. and Gupta, P. K. 1981. Effects of high temperature on chiasma frequency in irradiated Chrysanthemum segetum L. In Perspective in Cytology and Genetics. Eds. Manna, G. K. and Sinha, U. Proc. 3rd All India Cong. Cyt. Gen. Hindesia Delhi 3: 549.

Sybenga, J. 1975. Meiotic Configurations. Chap. 1-3. Springer Verlag, Berlin, New York.

Whitefield, J. F., Brohee, H. and Yondale, T. 1964. The effect of X-radiation on the chromatin structure and histone components of rat thymocite nuclei. Expt. Cell. Res. 36: 341-353.

Wuu, K. D. and Grant, W. F. 1967. Chromosomal aberrations induced by pesticides in somatic cells of Vicia faba. The Nucleus 10(1): 37-46.

Yost, H. T. and Benneyan, R. N. 1957. The effects of combined radiations on crossing over in Drosphila melanogaster. Genetics 42: 147-160.

Zakharov, I. A. and Ingevechtomov, C. G. 1963. Effects of X-irradiation and high temperature on the process of crossing over. Trudi Moscow obscheshtova Ispitateli Prirodi 7: 194 197. 